\title{
Base Abandonments by Low-Cost Carriers
}

Article in Journal of Air Transport Management · June 2016

DOI: $10.1016 /$ j.jairtraman.2016.06.008

CITATIONS

4

3 authors, including:

Renato Redondi

University of Bergamo

58 PUBLICATIONS 480 CITATIONS

SEE PROFILE
READS

188

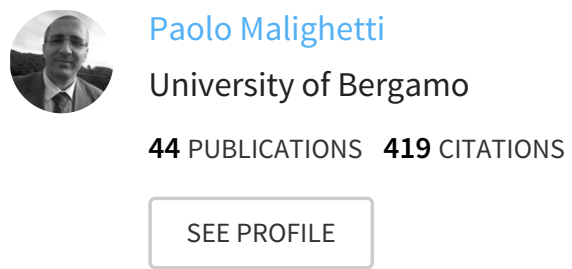

Some of the authors of this publication are also working on these related projects:

Project

Aviation economics View project

Project

"Re-discovering the Sources of Territorial Sustainability. Institutions for Development and Advanced Human Welfare" (“Excellence Initiatives” Program) View project

All content following this page was uploaded by Renato Redondi on 12 June 2016. 


\title{
Base Abandonments by Low-Cost Carriers
}

Paolo Malighetti, Stefano Paleari and Renato Redondi

\section{Address for Correspondence}

Renato Redondi, e-mail: renato.redondi@unibg.it

Via Pasubio 7b - 24044 Dalmine (BG) , Italy. Phone (+39) 0352052092 Fax (+39) 02700529452

\section{Paolo Malighetti}

Associate Professor, University of Bergamo. Dept. of Management, Information and Production Engineering, e-mail: paolo.malighetti@unibg.it

\section{Stefano Paleari}

Full Professor, University of Bergamo, Dept. of Management, Information and Production Engineering, e-mail : stefano.paleari@unibg.it

\section{Renato Redondi}

Associate Professor, University of Bergamo. Dept. of Management, Information and Production Engineering,

\begin{abstract}
:
This paper is the first attempt to systematically investigate the phenomenon of base abandonments by low-cost carriers (LCCs) in the world, from 1997 to 2014. Our results identify 109 cases where the LCCs decreased their presence in airports by at least 50 per cent in terms of offered seats. In 28 cases, the LCCs completely abandoned the airports. The incidence of downsizing is significantly reduced for important base airports. The abandonment by LCCs can be reversed, even though this is not very likely; in only 7.3 per cent of cases the same LCCs recovered full capacity. The impact on airports of LCC abandonments depends on the carrier level of dominance. The presence of middle size alternative airports increases the likelihood of downsizings.
\end{abstract}

Date of the final version: $8^{\text {th }}$ April 2016 
KEY WORDS: Low-Cost Carriers, Base Abandonment, Based aircrafts, Airport-airline relationship

\subsection{Introduction}

A recent study on airport competition, the report commissioned by ACI Europe to Copenhagen Economics (2014), discussed airline switching, that is the ability of an airline to relocate its services, as a factor generating competitive pressure on airports. One key finding was that about 15-20 per cent of routes opened and closed each year on account of airlines redeploying their fleets to maximize profitability. Such airline instability is a threat to an airport's ability to correctly invest and plan its future developments and may detrimentally affect the economy of the airport's surrounding areas.

An extreme form of airline instability is de-hubbing, by which the hub carrier abandons the airport. Previous studies have shown that de-hubbing is most often irreversible. The fact that all main hubs nowadays include in their master plans a worst-case de-hubbing scenario speaks volumes about the gravity of the perceived risk. Similarly, low-cost carriers (LCCs) can abandon or reduce their presence significantly in airports.

In replies to an Airports Council International (ACI) report, the IATA (2013) remarked that 'point-to-point' carriers, primarily LCCs, are responsible for the majority of switching activities, because their business model allows changing airports easily. Compared to de-hubbing, where the relationship between hubs and hub carriers is generally balanced, and in some cases even symbiotic, the market power in switching is markedly on the LCC side.

Indeed, some LCCs are famous for their occasionally aggressive approaches to obtain favourable deals with airports and other suppliers, and often we read newspaper reports about LCCs threatening to abandon airports. In 2013 Ryanair cut flights from London Stansted, its 
main base, because of increased fees ${ }^{1}$. More recently, the Irish carrier threatened to withdraw all aircraft based at Oslo Rygge, after the Norwegian government announced a new passenger $\operatorname{tax}^{2}$. A threat of abandonment can be a very effective deterrent against airports' untoward behaviours, such as planning an increase in charges. Probably, this is because a component of leisure demand can be geographically diverted by low fares (affecting the so-called footloose passenger). The issue of LCCs abandoning bases has been covered so far only with anecdotal evidence.

We intend to examine how frequently LCCs abandon an airport completely or partially, whether this is an increasing or decreasing trend, and whether it is a European phenomenon or is common among LCCs the world over.

We analyse the variation in seats offered at airports. Our analysis covers 813 airportlow cost carrier (LCC) pairs in which the carriers offered at least 500,000 seats annually. Further, even if point-to-point carriers do not hub, they have bases where aircrafts stand overnight and some logistic activity takes place. We consider the de-hubbing process similar to aircrafts leaving a base airport.

The remainder of this paper is organised as follows. Section 2 reports the relevant literature on the LCC-airport relation. Section 3 describes the data and research methodology, section 4 includes descriptive statistics of the dataset, and section 5 reports and analyses the results of the empirical analysis. The final section concludes and proposes directions for further research.

\footnotetext{
${ }^{1}$ http://www.bbc.com/news/uk-england-essex-21631597

${ }^{2}$ http://www.ch-aviation.com/portal/news/42836-airlines-warn-of-repercussions-over-norways-new-flight-tax
} 


\subsection{Literature review}

\subsection{LCC and airport relation}

There is wide agreement that the development of LCCs and airport commercialization significantly changed the airport-airline relationship. An understanding of this relationship would shed light on the reason for generating instability and abandonments since they too depend on the how LCCs choose their airports and on their long-term relationship. For a complete review of the topic, see the work of Graham (2013), who analyses all the features affecting the airport-LCC relationship. She finds that 'LCCs choose airports that meet the needs of their operating model, whilst taking into account the extent of airline and airport competition,' with higher airport competition welcomed by LCCs, most probably because the presence of alternatives increases the bargaining power of LCCs (Gillen and Lall, 2004). The low-cost model tends to serve airports offering low aeronautical charges and other user costs or airports that are flexible in negotiating deals (Francis et al., 2003, 2004; Barrett, 2004). Nevertheless, the conclusion of Graham (2013) is that 'not all the evidence pointed to airport costs being the overriding influencing factor'. Moreover, the literature is not exhaustive on the topic because it focuses on factors affecting LCC airport choice without attempting to rank them. One notable exception is Warnock-Smith and Potter (2005), who through a survey of eight European LCCs find that the demand for low-cost services is the most important choice factor, with aeronautical charges ranked fourth. The recent move of LCCs for a primary airport even in Europe indirectly confirms that the level of airport charges is not the only factor determining LCC airport choice.

Gil-Moltó and Piga (2008) analysed the exit and entry strategy followed by easyJet, Ryanair, and British Airways during 1997-2004. They find the possibility of entry and exit more likely in a large market. If we interpret this as LCC preference for a known market, it 
confirms the proposition that demand is one of the most important factors for airport choice. Dennis (2007) found that low-cost airlines perform best on dense routes involving no major airports and leisure routes between northern and southern Europe but reveal little growth in thin north European routes. The fact that LCCs enter into some kind of 'nowhere' airport does not mean that they do not care about the level of demand, but that their evaluations are based on a greater catchment area, as suggested by Dennis (2007). Thus, the first reason for LCCs to reduce services could be the decrease in expected demand for LCC services. Among the possible reasons for reduction in demand, the deterioration of socio economic conditions appears the strongest.

LCCs take decisions on their airport entry and exit in the light of their overall network development. Dobruszkes (2013) analyses the evolution of the LCC network in Europe and finds that the network evolved by increasing its average route length and expanding toward eastern Europe but remaining mainly focused on the intra-Western market and large cities and tourist destinations. Wit and Zuidberg (2012) highlight that the new routes opened by LCCs in Europe progressively became thinner and less densely served. They argued that this represents a sign of growth limitation that could lead to a change in LCC strategy in the future. They hypothesize the possible greater focus on primary airports and LCCs engaging in codesharing agreements.

The progressive shrink of newly introduced routes (Wit and Zuidberg, 2012) can also deter LCCs from exiting their existing airports from where they offer more dense routes. This prediction is partially corroborated by Dobruszkes (2013), who finds relatively good service stability at the city level but significant volatility at the inter-city level. 
Small airports that are not suitable for potential strategy switch and particularly those that have accommodated LCC services in recent years with less dense routes are potentially exposed to a higher risk of abandonment.

An important aspect of previous findings is that the majority of studies relate to Europe and that the findings cannot be easily transferred to the rest of the world. For example, in the United States, where the low-cost model was introduced during the seventies, LCCs have increasingly developed hubbing activities, departing from the point-to-point model (Wit and Zuidberg, 2012).

The few studies relating to the Asia-Pacific region highlight that the scarcity of secondary airports and the presence of other barriers cause LCCs to choose the same primary airports served by traditional airlines (Forsyth, 2003; De Neufville, 2008). Having dedicated low-cost terminals as well as other advantages is another factor distinguishing those areas from Europe.

Since the development process and some key features vary across countries, we expect the intensity of LCC downsizing to be geographically heterogeneous. As discussed by Winston and de Rus (2008), air transport regulation and privatization significantly differ among Countries and macro regions, so affecting the competitive landscape and the performances of their aviation systems. This limits the comparability among areas and the ability to identify common behaviours that affect LCCs downsizing around the world.

\subsection{Benefits of LCC presence}

The entry of LCCs can directly benefits consumers by offering services at lower prices compared to traditional carriers, and indirectly by generating price reductions also on 
routes offered by other carries, due to the positive effect of direct, adjacent and potential competition (Morrison 2001). To attract LCCs and increase traffic, some airports developed dedicated LCC terminals as a way to gain a competitive advantage at least for a time window (Njoya and Niemeier, 2011).

However, as pointed out by Graham (2013), previous literature has not clearly identified the financial benefits for airport of LCC services. Analyses of commercial revenue often provide controversial results; in some studies, few impacts are detected due to the extremely marginal commercial infrastructure at the LCC airport. Bottaso et al. (2012) studied a UK airports sample over the 2002-2005 period and investigated whether LCCs had any impact on the airports' total factor productivity (TFP). They find that 'empirical results are consistent with the hypothesis that conspicuous entry of LCCs on European markets has impacted positively on the vertical chain by facilitating airports' productivity improvements'.

In contrast, as mentioned at the beginning of this section, LCCs were undoubtedly successful in terms of passenger growth generated in several airports (from less than 1 million passengers to 9 million in Bergamo Airport and from less than 5 million in the beginning of 2000 to about 20 millions in London Stansted). In Europe, during the early 2000s, the illusion of a traffic boom, thanks to low costs irrespective of airport and territorial features, appeared to come true.

An increase in number of passengers is strongly beneficial for airports with unused capacity. This may pose some questions on the benefit of LCC presence in the long run, given that at some points airports need to invest to achieve adequate capacity. However, this is more a theoretical point since it will take decades to reach capacity problems at most LCC airports. In particular, benefits exist for small airports for whom the only chance to remain in the market is that their indivisible fixed cost reach the break-even passenger volumes. For 
example, after the EU commission (2013) proposed to stop aiding the operating costs of small airports (with a transitory time window of 10 years), the most reliable solution for the airports not yet in breakeven due to limited size was a high growth perspective. Attracting LCCs appear to be the only chance to follow this path.

\subsection{Effect of LCC abandonment}

Airline instability can severely affect the ability of airports to plan their future investments and development. In his book, Burghouwt (2007) describes the instability that networks generate and the consequent difficulties in terms of airport planning, which requires airports to depart from their traditional plans to a more flexible plan through future investment.

Most of the literature has focused on the effects of de-hubbing. Redondi et al. (2012) showed the de-hubbing effect likely to be irreversible at least in terms of hub connectivity provided. Bilotkach et al. (2015) showed that in case of the Malev de-hubbing, new services mostly provided by LCCs quickly replaced the Malev offer, even if the lower fares of the new services were not always able to compensate the welfare loss generated by the lower frequencies offered.

Airline de-hubbing and LCC service reduction should generate different effects. Hubs attract passengers who otherwise would not pass through the airport, and, thanks to these additional passengers, more intercontinental direct services can be offered.

In contrast, LCCs offer point-to-point services, and, thus, in a strong competitive environment, if an airline exits a market on the territory, other airlines would quickly enter the market and serve it. 
Nevertheless, we need to consider the ability of LCCs to stimulate demand, even by opening up new markets previously not operated. The open question is whether once a market has been 'discovered' or 'stimulated', other carriers would be attracted by the market and be able to serve it, or, in contrast, whether without the LCC's presence, the market would stop growth and go back to the pre-LCC situation. An even more negative assumption is that 'if no LCC is able to commercially serve the market none else will be', implying that airports abandoned by LCCs have almost no chance to recover traffic. In this context, a recent case is that of the Forli airport in Italy: the airport went bankrupt and closed all activities in 2013 after its main carrier, Ryanair, abandoned the airport in $2010^{3}$. Finally, since several LCCs are aggressive in entering into profitable deals, a LCC may even downsize its capacity at an airport in order to warn of what the airport could incur if it leaves completely. In this scenario, the downsizing would most probably be temporary.

From an airline perspective, point-to-point LCCs typically do not benefit from economies of scale or density in the same way as traditional carriers do at their hubs (Brueckner and Spiller, 1994). So even the presence of LCCs switching costs when they abandon their bases is not generally evident. This specific topic has been almost neglected by literature. We can assume that even if LCCs do not have frequent flyer programs, changing airports involves new marketing effort and generate switching costs for passengers. Furthermore, as Bottaso et al. (2012) showed that LCCs improved the airport operative efficiency, changing airports may generate a short-term loss of productivity if the alternative airports are not ready to meet LCC requirements. Finally, when LCCs move operations to another airport, the airlines may need to re-optimize scheduling and maintenance activities, and recruit and train new labour forces.

\footnotetext{
${ }^{3}$ At its maximum in 2008, Ryanair offered 560,000 seats in the Forlì airport.
} 
To the best of our knowledge, this paper is the first attempt to systematically investigate the cases of base abandonments by LCCs in the world, together with the main variables driving the phenomenon. The research aims to better understand how the competitive environment and switching costs affect the LCC choice to reduce significantly its services at an airport, especially when the airport is a base.

\subsection{Data and methods}

In this analysis, we aim to identify significant $\mathrm{LCC}^{4}$ reductions at based airports from the number of annual seats offered. We retrieve information from the annual schedules provided by the $\mathrm{OAG}^{5}$ between 1998 and 2014, a period where the two major aviation markets, Europe and US, were already both liberalized. We analysed the number of seats offered at each airport and showed the number of aircrafts the LCCs based at each airport. We considered the airport-LCC pairs where the carriers offered at least 500,000 seats per year and so excluded the airports where the LCC presence is limited to very few routes. At the same time, this choice allows us to include airports having traffic volumes of almost 1 million passengers per year with LCCs dominating.

\footnotetext{
${ }^{4}$ We define LCCs according to Morandi et al. (2015). The list of LCCs included in this study is reported in appendix.

${ }^{5}$ The OAG dataset includes information about all passenger scheduled flights in the world. For each flight the dataset supplies the information about the departure and arrival airports, scheduled departing and arrival times, scheduled date and operating carriers.
} 


\subsection{Methodology for estimating number of based aircrafts}

To the best of our knowledge, data about the exact number of aircrafts based is not available for the entire period analysed (1997-2014), nor for most of secondary airports. The number of based aircrafts has been estimated by analysing the schedule provided by OAG. The algorithm developed analyses the timetable starting from early morning and estimates the number of aircrafts from the number of departures. The algorithm starts by assuming a minimum turnaround time (tt) as well as that a based aircraft departs from the base no later than a certain hour in the morning (h_stop). tt ranges from 15 to 40 minutes and the $\mathrm{h} \_$stop ranges from 9:00 to 10:00 in the morning. The higher aircraft utilization and shorter average stage distance typical of LCCs allow us to consider this hypothesis reliable. The algorithm counts the number of aircrafts departing from early morning (4 o'clock) up to h_stop and then subtracts the number of aircrafts landed between 4:00 in the morning and h_stop - tt. It compares the stability of the results by modifying tt and h_stop in the cited ranges. The results are compared by applying a similar algorithm counting the number of aircrafts returned to the base; that is, by counting the number of landed aircrafts between $\mathrm{h}$ _start (from 17:00 to 20:00) up to 2 hours after midnight less the number of departed aircraft between h_start+tt and 2:00 in the morning. We tested the goodness of our estimation by comparing the real and estimated number of based aircrafts for the main airports in the last two years. The estimation error was by one aircraft in the majority of cases.

\subsection{Methodology and variables}

The aim of the statistical analysis is to shed light on the features that favour significant capacity drops by LCCs. This analysis is tested in a multivariate setting. We employ a logistic model for panel data composed of airport-airlines pairs for the period 
1997-2013 with random effects, where the dependent variable is equal to 1 in year t for LCCs that dropped their airport capacity by more than 20 per cent (Y20). We clustered the standard errors by airport-LCC pair to account for slow time-variant variables, as for the size of alternative airports. The panel is unbalanced (average time length 9.5 years) since a large number of new airports have been progressively included in the expansion of the LCC network. Table 1 gives the variables' definitions.

Our multivariate analysis investigates whether the size and relevance of the LCCs' activities at the airport have a role in the withdrawal decision. Additionally, we consider the competitive framework in terms of i) the level of dominance exercised by LCCs, measured as the market share provided by a LCC at an airport, ii) the presence of alternative airports in the area and iii) the relative size of the other LCCs services at the airport. We also account for the elements facilitating the LCC switch choice as well as the fact that they may induce the airport to be more prone to offer incentives to avoid LCC abandonment. Finally, we control for the market trend of the country of reference and the expansion or shrinkage of LCC network.

We also control for the years the LCC is providing service at that airport. On one side, the strong dynamics of LCC that rely on a trial-and-error mechanism may suggest a greater tendency to drop traffic within the first few years, but this phenomenon is more likely to happen when the LCC has only limited capacity. On the other side, several years after the initial settlement, it is more likely for the LCC to enter into a new negotiation period with the airport (for renewal of contract on charges and other 'conditions of use'). Moreover, if the LCC has been serving the airport since long, the airport would have probably grown and now there could be a need for either more market saturation or new airport investment that the airport operator cannot easily afford because of the low fare paid by the LCC. Indeed, Button 
(2012) argues that the low-cost business model may have harmed the airport ability to recover full costs. The summary of the variables included is in table 1 . All the variables have been computed by the OAG scheduled flights database.

- Table 1 here -

\subsection{Descriptive analysis}

The sample consists of 813 airport-LCC pairs with 5,799 overall observations. Examples of the selected airport-LCC pairs are Gatwick-easyJet, Gatwick-Ryanair, StanstedRyanair etc.. We monitor each airport-LCC pair for more years, so that accounts for passing from 813 to 5,799 total observations. On average, we have a track record of $7.1(5799 / 813)$ years for each airport-LCC pair. The sample involves 69 LCCs and 406 airports. While the first three LCCs, namely, Ryanair, Southwest, and EasyJet, were observed in more than 50 airports and accounted for 29 per cent of all the airport-LCC pairs, 25 LCCs were observed in more than 10 airports, accounting for 85 per cent of the airport-LCC pairs. Only one LCC with a volume exceeding the 500,000 seats threshold served 58 per cent of the airports in the sample.

Overall, the number of observations increased from 124 in 1997 to 500 in 2014. Coherently, with different maturities of LCCs around the world in 1997, the majority of airport-LCC pairs were observed in North America, with the number of observations almost double that in the European Union (65 vs. 39). In contrast, in 2014, a large majority of observations were from the European Union, with 282 against 148 in North America.

- Table 2 here - 
In term of bases, our algorithm identified 332 airport-LCC pairs with at least five aircrafts: 170 in Europe, 113 in North America, and the remaining spread across South America, Asia, and Australasia. We do not identify bases with more than five aircrafts in the Middle East and Africa.

- Table 3 here -

The number of aircrafts based at an airport is clearly correlated with the level of seats supplied since it is not sensible to base an aircraft at a specific airport if the majority of flights of the aircraft do not depart from or land in that airport. Nevertheless, the relation is not linear and straightforward since it could be that enough seats are supplied at a specific airport without having an aircraft based there. Figure 1 depicts the scatterplot of the relation between number of seats and aircrafts based; the figure confirms the presence of a variety of situations especially in the range of 1-3 million seats supplied at the airport by LCCs.

- Figure 1 here -

\subsection{Results}

\subsection{Trend and frequency of LCC service reduction}

Table 4 reports the downsizing at airports with supply greater than 500,000 annual seats. Overall, about one-third (33.8 per cent) of the airports considered suffered from a service reduction of at least 20 per cent. In contrast, LCCs left an airport completely much more rarely; we identified 28 cases, that is, 3.8 per cent of the sample analysed.

Service reduction was quite limited between 1998 and 2005, with the number of downsizings (higher than 20 per cent) ranging between three and seven airports per year. 
During these seven years, we reported only four cases of complete airport abandonment. Year 1999 shows the lowest level of service reduction, with only three cases, all of them with reductions less than 50 per cent of the previous supply level. Data confirm that the September 11 crisis had only a marginal effect on LCC activities, which in fact gained from difficulties suffered by several traditional carries.

In contrast, the 2008-2009 period represents the peak years, when 96 airports (50 in 2008 and 46 in 2009) suffered from service reductions by LCCs. Among them, 22 airports in 2008 and 13 in 2009 suffered from a supply reduction greater than 50 per cent, with six airports completely abandoned. The spread of the economic crisis and deteriorated socioeconomic expectations especially in Europe, and to a lesser degree in US, could be the main reasons for that peak in downsizings. The other areas were not so strongly affected by the crisis.

In following years, the number of downsizings decreased from its 2008-2009 peak. A possible reason may be that airports, as a defensive move, have tried to negotiate medium/long-term contracts with their LCC (Starkie, 2012). In 2010, while the overall cases of service reduction dropped to 20 , the level of abandonment remained quite high, with five cases. Year 2014 registered a generalized growth in almost all markets; both national and international markets reported a growth rate of around 3-4 per cent, and in Europe, 80 per cent of airports increased their passenger traffic (ICCSAI, 2015). This return to growth generated a limited number of downsizings, but half of them were complete airport abandonments. If we consider the airport-LCC pairs at the beginning of 2000 and the size of LCC presence in 2014, we find that the share of downsized airports exceeded 10 per cent in 2008 and 2009 but dropped to 1.2 per cent in 2014. Even when we consider different LCC 
presences, a well-defined time trend in terms of propensity to downsize does not seem to exist.

- Table 4 here -

Table 5 reports the number of downsizings by LCCs with more than five aircrafts based. The overall number of downsizings dropped from 275 to 88 and the share of base airports that suffered a service reduction is 26.5 per cent instead of 33.8 per cent when we consider all airports of the sample. Overall, only one airport hosting more than five aircrafts was completely abandoned. This is the case of the George Best Belfast City Airport in the United Kingdom, which was abandoned by Ryanair in 2010 due to its limitations of airport operability, when new investments in improving the runaway were further delayed ${ }^{6}$. Even if traffic volumes and number of aircrafts based cannot be disentangled, they remain statistically correlated, and the data suggest that being a base airport reduced the probability of suffering from downsizing. This may be related to the presence of higher switching costs, because when several aircrafts are based at an airport, logistic activities are most likely to be in place, for example, the presence of maintenance activities and aircrew living in the surrounding areas.

- Table 5 here -

The analysis by geographical area (Table 6) confirms that European airports suffered more from downsizing in both overall and relative terms. In Europe, almost 40 per cent of airports considered suffered from a service reduction compared to 27.5 per cent in North America. The LCCs' hub activities in North America may be one of the reasons for the

\footnotetext{
${ }^{6}$ http://www.telegraph.co.uk/travel/travelnews/7978246/Ryanair-scraps-all-flights-to-Belfast-in-latestairport-row.html
} 
limited downsizing in the United States compared to Europe and South America. Another important difference is the investment of airlines in terminals that increase switching costs and encourage the long-term relation between the airport and airline. This phenomenon is far more limited in Asia, most probably because of limited choice in the number of alternative airports. In fact, the only case of abandonment in Asia was that of the Indonesian Polonia International Airport by Sriwijaya Air in 2013, motivated by the opening of the newly constructed Kualanamu International Airport.

\section{- $\quad$ Table 6 here -}

To investigate the role of airport competition in determining airport downsizings by LCCs, we report in figure 2 the proportion of downsizing in the presence of alternative airports (i.e. airports located within $100 \mathrm{~km}$ and offering scheduled services), for the two major markets of Europe and North America. Interestingly, the vast majority of airports in Europe suffering downsizing higher than $20 \%$, operated under competition by alternative airports, almost $72 \%$. This figure reflects the higher level of competition in Europe by other airports operating in the same catchment area. For North America, that valued drops to $50 \%$. However, figure 2 also shows that the proportion of downsizings in the presence of alternative airports increases when considering the more severe cases. For Europe, $81 \%$ of cases of complete abandonments happened in presence of alternative airports. For North America, all cases of the complete abandonments happened with alternative airports. The presence of alternative airports from which LCCs could continue to serve a specific market, seem to play an important role in explaining downsizings.

- Figure 2 here - 
Given Europe is the region more affected by LCC downsizings, Table 7 shows the number of downsizings in the main European markets. Interestingly, in percentage terms, the countries most affected by LCC reduction higher than 20 per cent are Germany, Poland, and the United Kingdom. On the other hand, Italy, France, Sweden, and Norway show a lower impact with respect to overall number of airport-LCC pairs considered in the analysis. However, when considering more severe cases, Italy reports the highest impact, with almost one case in ten (9.1 per cent) where LCCs completely abandoned airports. The only case of complete abandonment of a Spanish airport is that of the Granada airport by Ryanair in 2010 . In this case, the airport operator did not renew its long-term agreement with Ryanair after the city of Granada refused to subsidize the services ${ }^{7}$. The few cases of downsizing by Ryanair widely publicized in Europe, that is, those relating to its main base airports London Stansted and Dublin, the Spanish airport of Girona Barcelona, and the German airport of Frankfurt Hahn, motivated by airport charges considered too high or the airport operators' intention to increase them, involved only partial downsizing. London Stansted suffered a 24 per cent capacity reduction by Ryanair in 2012 . However, Ryanair's capacity later recovered almost to its pre-abandonment level. The same holds for Dublin, whose capacity offered by Ryanair decreased one-third in 2012 but partially recovered later. As for Girona Barcelona and Frankfurt Hahn, Ryanair's capacity declined by 63 per cent and 48 per cent from its peaks in 2008 and 2007 respectively, but so far there is no sign of recovery in these cases.

- Table 7 here -

\footnotetext{
${ }^{7}$ http://centreforaviation.com/analysis/ryanair-in-the-dock-46014
} 


\subsection{Airline specificities and airport dominance}

Table 8 reports the top airlines in terms of number of downsizings. Ryanair is the LCC responsible for the highest number of downsizings in the world, with 57 downsizings and 6 complete abandonments; the other airports registered not more than three abandonments. European airlines with a strong charter history/attitude show a higher rate of downsizing; for example, Airberlin and TUIfly. Southwest ranked fourth in overall terms, but considering its network size, the number of downsizings is similar to that of Ryanair. However, when considering complete abandonment, we find only one case pertaining to Southwest; this is also the sole case of complete abandonment in North America (Table 5) suffered by the San Francisco airport at the hands of Southwest in 2001 due to high airport costs and flight delays. However, the airline returned to San Francisco six years later in 2007. The Latin LCC Gol appeared more aggressive, with 17 downsizings and three abandonments, the Brazilian airports of Belo Horizonte/Pampulha and Campinas-Viracopos and the Chilean airport of Comodoro Arturo Merino Benítez, all abandoned by Gol between 2008 and 2013.

- Table 8 here -

For all the airlines reported in Table 9, abandonments occurred at airports with low LCC dominance $^{8}$, that is, lower than in cases where LCCs downsized their activities without complete abandonment. This could be because a highly dominated airport tends to accommodate all airline requests in order to avoid complete abandonment.

Excluding complete abandonments, no clear trend is seen between the magnitude of downsizing and dominance of airport. The average dominance is similar for seat reduction ranging from 20 to 80 per cent for almost all the airlines analysed.

\footnotetext{
${ }^{8}$ LCC dominance is the share of LCC at the airport measured in terms of offered seats on scheduled flights.
} 
Similarly, our analysis of the average size of airports where downsizing takes place does not show a clear trend. Downsizing higher than $70-80$ per cent tends to occur in smaller airports, but the difference is not statistically significant. For example, the few strong seat reductions by Southwest were in big airports.

\section{- Table 10 here -}

Finally, one of the main questions is whether downsizing is temporary and motivated by tactical and contingency aspects or whether it is permanent, like, when an LCC downsizes its offer at an airport, it is unlikely to invest again in the future. Table 11 synthesizes the results by reporting the number of cases in which the LCC recovered the pre-downsizing traffic volumes. Overall, this occurred in 42 out of 275 cases. In all cases where the magnitude of downsizing is more consistent, for example, in all the 109 cases with seats reduction greater than 50 per cent, the rate of recovery dropped to 7.3 per cent. Only in one out of 28 complete abandonments, the LCC went back to the airport and recovered to the preabandonment traffic level. This is the already mentioned case of Southwest abandoning San Francisco in 2001 and then returning to the airport in 2007. In the final year of the analysis, 2014, the carrier offer at the airport was three times greater than that before the abandonment.

Cases of downsizing in base airports (those with at least five aircrafts based) are less frequent. We observed a complete abandonment in only one case. That is, the already mentioned case of the Belfast airport abandoned by Ryanair in 2010 when the airline had 13 aircrafts based. However, even if downsizings are rarer for base airports, their chance to recover traffic is significantly lower. From among the 26 downsizings greater than 50 per cent at base airports, only in one case the LCC returned to its pre-abandonment traffic level. 
This is the case of Jet2.com, which reduced its offered seats at the Newcastle Airport by 61 per cent in 2009, compared with its peak in 2007, but later increased its presence to the above initial level ${ }^{9}$. This shows that if the downsizing involves a certain amount of logistic activity or requires a strategic long-run choice, like the decision not to invest anymore in a specific market or to find alternative airports to continue serving the area, the choice is most likely to be irreversible.

- Table 11 here -

\subsection{Econometric results}

- Table 12 here -

Table 12 reports the results of empirical analysis to identify the determinants of traffic reduction greater than 20 per cent in airports where LCCs offered at least 500,000 seats/year. The analysis shows that LCC drops are influenced by market trends. In case the market is expanding in a specific country (Country_growth), the probability of a drop decreases. Similarly, LCCs are more likely to abandon or decrease their offers in their main airports/bases while experiencing traffic shrinks or periods of slow growth. Not surprisingly, 2008 and 2009 registered the peak of drops mainly in Europe because the overall market as well as most LCC airlines suffered the effect of the economic crisis.

Moreover, LCCs more easily drop their capacity in airports where their presence is scarce. In airports where the volume offered is very high, LCCs find it more difficult to drop a substantial share of capacity; most probably, this is because the alternative markets may not

${ }^{9}$ In the San Francisco downsizing, when Southwest abandoned the airport in 2001, the carrier had three aircrafts based at the airport, and so this case was not included in the base airport group (requiring at least five aircrafts based). 
be big enough to absorb the diversion of several aircrafts. Furthermore, the greater the effort of the LCC in the airport (number of seats), the higher is the probability of the airport representing a successful market in the past.

The maximum number of aircrafts based at the airport is also negative and significant, meaning that investments in logistic activity set by LCCs in setting up a crucial base at that airport generate, ceteris paribus, a high level of switching cost that tends to discourage LCC drops.

The econometric model confirms that LCCs tend to avoid head-to-head competition with other LCCs; when other LCCs serve the airport, the likelihood of downsizing increases proportionally with the relative size of their offers.

In addition, our results show that seat reduction is more likely after several years, suggesting that the need of renewing contracts between LCCs and airports can result in a drop; furthermore, after several years, the airport can become less attractive to a LCC because of greater market saturation.

Reduction of activity is less likely if the LCC dominates the airports, most probably because strongly dominated airports are more worried about the threat of abandonment and tend to provide better and quicker service to LCCs in order to avoid downsizings.

The results additionally show that the relationship between the numbers of seats provided by the various airports within a radius of $100 \mathrm{~km}$ appears to have a U-shaped form. This suggests that the presence of alternatives may induce LCCs to switch between airports serving the same conurbation owing to the competition between airports to attract services from the same LCC. Indeed, the distance from alternative airports is coherently negative; that is, closer the alternative airports, greater is the likelihood for the LCC to drop. In contrast, this increasing trend stops when the size of the alternative airport become greater, suggesting 
that the alternative airport is more likely to become a big congested primary airport (as London Heathrow in Europe) or to be an alliance stronghold (as Frankfurt or Paris Charles de Gaulle).

\subsection{Conclusion}

This analysis covered 813 airport-LCC pairs in which the carriers offered at least 500,000 annual seats in the period. Our results identify 109 cases (13.4 per cent of the total number of airport-LCC pairs) where the LCCs decreased their presence in airports by at least 50 per cent in terms of offered seats. In 28 cases (3.4 per cent), the LCCs completely abandoned the airports. The highest number of abandonments occurred in years 2008 and 2009, corresponding to a slow-growth period of the air transport industry, decreasing significantly in the final year, 2014, which registered only four cases of LCC downsizings. Ryanair is the LCC responsible for the highest number of downsizings in the world, 22, six of which are cases of complete abandonment, followed by Air Berlin, Southwest, easyJet, and BlueJet.

The study also analyses the downsizing in which at least five aircrafts were based at the airport. The hypothesis is that if the airport is a relevant base, besides being beneficial in terms of revenue and local employment, the switching costs should increase for the airline. Findings identify 26 cases where the seat capacity of the LCC decreased by at least 50 per cent, over a total number of 332 airport-LCC pairs with at least five aircrafts based and only one instance of complete abandonment. That is the case of the Belfast City Airport, abandoned by Ryanair in 2011 due to runway limitations, when the planned runway extension was further delayed. The incidence of downsizing is 7.8 per cent in this case, much less that the 13.4 per cent computed for the complete sample. Therefore, a possible strategy 
by airports to protect themselves against downsizing involves trying to increase the LCC specific investment at the airport, as by becoming a base airport, or even a maintenance centre for the carrier.

Is the downsizing by LCCs reversible? Our analysis shows that out of the 109 cases of downsizing greater than 50 per cent by LCCs, in eight instances ( 7.3 per cent) the same LCCs recovered full capacity at the airports in 2014 . In contrast to de-hubbing, the abandonment by LCCs can be reversed, even though this is not very likely. Out of the 26 cases where LCCs reduced their capacity by at least 50 per cent from the relevant base airports, in only one instance (3.8 per cent) the LCC eventually resumed full capacity at the airport. That is, Jet2.com reduced its offered seats from the Newcastle Airport by 61 per cent in 2009, compared with its peak in 2007, but later increased its presence to above the initial level. This should spell a cautionary tale for LCC airports. Even if downsizing is significantly reduced for important base airports, once the LCCs decide to abandon them, they leave for good.

Airport competition significantly affects LCC downsizing. The likelihood of a drop of capacity is U-shaped relative to the size of airports located within $100 \mathrm{~km}$. It means that the presence of middle size alternative airports significantly increases the prospect of downsizings, as LCCs have other viable options to serve the local market. However, when there are no alternative airports, or they are very small and unattractive, the likelihood of downsizing decreases. Similarly, it decrease when the size of the alternative airports is high. In the latter case some obstacles to a LCC switching may emerge, as congestion, high airport charges, or a significant presence of full service carriers (such as in the alliance "strongholds" of Frankfurt or Paris Charles de Gaulle). In those cases, the airport operators are often unwilling or unable to meet the LCCs basic requirements. 
LCCs also tend to avoid head-to-head competition with other LCCs. The likelihood of downsizing is lower where they dominate the airport and there is no significant competition by other LCCs.

The ultimate impact of partial or complete abandonment on airport traffic depends on the LCC degree of dominance and the size of its operations. Since Ryanair had the highest level of dominance over its downsized airports, offering an average of 54 per cent of their seat capacity, these airports suffered most.

To reduce their overall risk, the LCC airports should avoid putting all their eggs in one basket. Unfortunately, besides being hardly news, that is not a matter of choice for most secondary airports.

Overall, the paper does not come without limitations. The worldwide approach provides insights about the common behaviour that characterized all LCCs. However, since there are significant differences among the considered markets in terms of regulation and privatization, a focus on each macro area is required to better identify policy recommendations. Furthermore, our sample excluded very small airports, those more vulnerable toward LCC downsizings.

Future steps in the research agenda could focus on the issue of LCC abandonments for the smaller airports with annual passengers lower than 500,000. Another future development of this work could further investigate the more severe cases of downsizings by contacting and interviewing the airport operators, in order to validate our findings and obtain new insights, and by deepening the level of analysis on the more homogeneous markets as Europe and North America. 


\section{References}

Barrett, S. (2004): 'How do the demands for airport services differ between full service carriers and low-cost carriers?', Journal of Air Transport Management, 10(1), 33-39.

Bilotkach, V., Müller, J., and A. Németh (2014): 'Estimating the consumer welfare effects of de-hubbing: The case of Malév Hungarian Airline', Transportation Research Part E, 66, 51-65.

Bottasso A., M. Conti, and C. Piga (2012): 'Low-cost carriers and airports' performance: empirical evidence from a panel of UK airports', Industrial and Corporate Change, 22(3), $1-25$.

Brueckner, J. K., and P. T. Spiller (1994): 'Economies of Traffic Density in the Deregulated Airline Industry', The Journal of Law and Economics 37(2), 379-415.

Burghouwt, G. (2007): Airline network development in Europe and its implications for airport planning. Ashgate, Aldershot

Copenhagen Economics (2012): Airport competition in Europe, Study commissioned by ACI EUROPE, June, www.seo.nl/uploads/media/2012 47_Airport_Competition_in_Europe.pdf

De Neufville, R. (2008): 'Low-cost airports for low-cost airlines: flexible design to manage the risks', Transportation Planning and Technology, 31(1), 35-68.

De Wit, J., and J. Zuidberg (2012): 'The growth limits of the low cost carrier model', Journal of Air Transport Management, 21, 17-23.

Dennis, N. (2007): 'Stimulation or saturation? Perspectives on the European low cost airline market and prospects for growth', Journal of the Transportation Research Board, 2007, 5259.

Dobruszkes, F. (2013): 'The geography of European low-cost airline networks: a contemporary analysis', Journal of Transport Geography, 28, 75-88.

Forsyth, P. (2003): 'Low cost carriers in Australia: experiences and impacts', Journal of Air Transport Management, 9(5), 277-284.

Francis, G., A. Fidato, and I. Humphreys (2003): 'Airport-airline interaction: the impact of low-cost carriers on two European airports', Journal of Air Transport Management, 9(4), 267-273.

Francis, G., I. Humphreys, and S. Ison (2004): 'Airports` perspectives on the growth of low cost airlines and the remodeling of the airport-airline relationship', Tourism Management, 25(4), 507-514.

Gillen, D., and A. Lall (2004): 'Competitive advantage of low-cost carriers: some implications for Airports', Journal of Air Transport Management, 10(1), 41- 50.

Gil-Moltó, M.J., and C.A. Piga (2008): 'Entry and exit by European low-cost and traditional carriers', Tourism Economics, 14(3), 577-598. 
Graham, A. (2013): 'Understanding the low cost carrier and airport relationship: A critical analysis of the salient issues', Tourism Management, 36, 66-76.

IATA (2013), Economics Briefing No 11: AIRPORT COMPETITION V. 1.2, November. www.iata.org/whatwedo/Documents/economics/airport-competition.pdf

Morandi, V., Malighetti, P., Paleari, S., and R. Redondi (2015): 'Codesharing agreements by low-cost carriers: An explorative analysis', Journal of Air Transport Management, 42, 184-191.

Morrison, S. A. (2001): 'Actual, Adjacent, and Potential Competition: Estimating the Full Effect of Southwest Airlines', Journal of Transport Economics and Policy, 35 (2), 239256.

Njoya, E.T., and H-M.Niemeier (2011): 'Do dedicated low-cost passenger terminals create competitive advantages for airports?', Research in Transportation Business and Management, 1, 55-61.

Redondi, R., P. Malighetti, and S. Paleari (2012): 'De-hubbing of airports and their recovery patterns', Journal of Air Transport Management, 18 1-4.

Starkie, D. (2012): 'European airports and airlines: Evolving relationships and the regulatory implications', Journal of Air Transport Management, 21 40-49.

Warnock-Smith, D., \& Potter, A. (2005): 'An exploratory study into airport choice factors for European low-cost airlines. Journal of Air Transport Management, 11(6), 388-392.

Winston, C., and G. de Rus (2008): 'Aviation Infrastructure Performance: A Study in Comparative Political Economy', Washington, Brookings Institution Press. 


\section{Tables}

\begin{tabular}{|c|c|}
\hline Variables & Description \\
\hline Seats_offered & $\begin{array}{l}\text { Number of seats offered by the LCC at the airport in year t- } 1 \text { in each } \\
\text { specific airport. We consider only those airports where LCCs offered } \\
\text { more than } 0.5 \text { million seats per year. }\end{array}$ \\
\hline N_aircraftbased & $\begin{array}{l}\text { Number of aircrafts based at the airport estimated using the procedure } \\
\text { described in the methodology section. We consider the maximum } \\
\text { number of aircrafts based at the airport to measure the maximum size of } \\
\text { the airlines' investments in terms of logistic activity. }\end{array}$ \\
\hline N_year & Number of years the LCC is active at that airport. \\
\hline Mkt_share & $\begin{array}{l}\text { Market share of LCC at the airport measured as the share of offered seats } \\
\text { on scheduled flight at year } t-1 \text {. }\end{array}$ \\
\hline LCCcompetitor & $\begin{array}{l}\text { The relative size (in term of seats offered) of competing LCCs at the } \\
\text { airport at year t-1 }\end{array}$ \\
\hline$L C C \_$growth & $\begin{array}{l}\text { Annual growth of LCC measured by the percentage change of overall } \\
\text { number of seats offered in year } t \text {. }\end{array}$ \\
\hline Alt_airport_size & $\begin{array}{l}\text { The sum of seats offered by airports located within a radius of } 100 \mathrm{~km} \\
\text { (Euclidean distance) from the airport. }\end{array}$ \\
\hline Country_growth & $\begin{array}{l}\text { Annual growth at country level (to which the airport belongs) measured } \\
\text { by percentage change of overall number of seats offered in year } t \text {. }\end{array}$ \\
\hline Alt_aiport_distance & Average weighted distance from alternative airports. \\
\hline Ryanair_dummy & Dummy equals 1 if the LCC is Ryanair. \\
\hline
\end{tabular}

Table 1.Description of variables 


\begin{tabular}{|c|c|c|c|c|c|c|c|c|}
\hline Year & Africa & Asia & Europe & $\begin{array}{c}\text { Middle } \\
\text { East }\end{array}$ & $\begin{array}{c}\text { North } \\
\text { America }\end{array}$ & Oceania & $\begin{array}{c}\text { South } \\
\text { America }\end{array}$ & $\begin{array}{l}\text { Overall n. of airport- } \\
\text { LCC pairs }\end{array}$ \\
\hline 1997 & & 9 & 39 & & 65 & & 11 & 124 \\
\hline 1998 & & 8 & 34 & & 74 & & 10 & 126 \\
\hline 1999 & & 6 & 40 & & 79 & & 11 & 136 \\
\hline 2000 & & 2 & 54 & & 98 & & 10 & 164 \\
\hline 2001 & & 3 & 61 & & 107 & 4 & 11 & 186 \\
\hline 2002 & & 4 & 83 & & 109 & 5 & 11 & 212 \\
\hline 2003 & & 2 & 110 & & 119 & 8 & 14 & 253 \\
\hline 2004 & & 2 & 138 & & 130 & 10 & 13 & 293 \\
\hline 2005 & & 4 & 172 & & 127 & 11 & 14 & 328 \\
\hline 2006 & & 9 & 195 & & 128 & 10 & 19 & 361 \\
\hline 2007 & & 9 & 215 & & 141 & 10 & 24 & 399 \\
\hline 2008 & & 14 & 232 & & 144 & 14 & 24 & 428 \\
\hline 2009 & 1 & 18 & 236 & & 137 & 15 & 24 & 431 \\
\hline 2010 & 3 & 17 & 243 & & 138 & 14 & 28 & 443 \\
\hline 2011 & 3 & 21 & 243 & & 144 & 12 & 34 & 457 \\
\hline 2012 & 2 & 24 & 256 & & 145 & 14 & 33 & 474 \\
\hline 2013 & 3 & 27 & 264 & 1 & 152 & 3 & 34 & 484 \\
\hline 2014 & 4 & 28 & 282 & 4 & 148 & & 34 & 500 \\
\hline
\end{tabular}

Table 2. Airport-LCC pairs by year and geographical area

\begin{tabular}{|c|rrr|}
\hline & \multicolumn{1}{|c}{$\begin{array}{c}\text { LCC- } \\
\text { airport } \\
\text { pairs }\end{array}$} & $\begin{array}{l}\text { N. of aircrafts } \\
\text { based }\end{array}$ & $\begin{array}{l}\text { N. of bases with at least 5 } \\
\text { aircrafts }\end{array}$ \\
\hline Africa & 4 & 5 & 0 \\
Asia & 50 & 222 & 17 \\
Europe & 443 & 2077 & 170 \\
South America & 67 & 289 & 25 \\
Middle East & 4 & 7 & 0 \\
North America & 228 & 1531 & 113 \\
Oceania & 17 & 104 & 7 \\
\hline Overall & $\mathbf{8 1 3}$ & $\mathbf{4 2 3 5}$ & $\mathbf{3 3 2}$ \\
\hline
\end{tabular}

Table 3. Airport-LCC pairs by geographical area 


\begin{tabular}{|c|c|c|c|c|c|c|c|c|c|c|}
\hline \multirow[b]{2}{*}{ Year } & \multicolumn{9}{|c|}{ Reductions in seat capacity by LCCs higher than } & \multirow{2}{*}{$\begin{array}{c}\text { \% of } \\
\text { downsizing } \\
\text { with respect } \\
\text { to the n. of } \\
\text { airport-LCC } \\
\text { pairs by year }\end{array}$} \\
\hline & $20 \%$ & $30 \%$ & $40 \%$ & $50 \%$ & $60 \%$ & $70 \%$ & $80 \%$ & $90 \%$ & $100 \%$ & \\
\hline 1998 & 7 & 6 & 6 & 3 & 1 & 1 & 1 & 0 & 0 & 5.6 \\
\hline 1999 & 3 & 3 & 3 & 0 & 0 & 0 & 0 & 0 & 0 & 2.2 \\
\hline 2000 & 5 & 5 & 3 & 3 & 2 & 1 & 1 & 1 & 1 & 3.0 \\
\hline 2001 & 7 & 6 & 5 & 5 & 4 & 2 & 2 & 1 & 1 & 3.8 \\
\hline 2002 & 7 & 5 & 2 & 1 & 1 & 1 & 1 & 1 & 1 & 3.3 \\
\hline 2003 & 6 & 5 & 3 & 3 & 3 & 2 & 1 & 0 & 0 & 2.4 \\
\hline 2004 & 3 & 2 & 2 & 2 & 2 & 2 & 1 & 0 & 0 & 1.0 \\
\hline 2005 & 5 & 3 & 1 & 1 & 1 & 1 & 1 & 1 & 1 & 1.5 \\
\hline 2006 & 8 & 4 & 4 & 4 & 3 & 3 & 3 & 2 & 1 & 2.2 \\
\hline 2007 & 15 & 14 & 13 & 11 & 7 & 6 & 4 & 1 & 0 & 3.8 \\
\hline 2008 & 50 & 41 & 33 & 22 & 15 & 11 & 9 & 8 & 4 & 11.7 \\
\hline 2009 & 46 & 31 & 21 & 13 & 12 & 9 & 5 & 2 & 2 & 10.7 \\
\hline 2010 & 20 & 17 & 16 & 14 & 9 & 7 & 6 & 6 & 5 & $4.5 \%$ \\
\hline 2011 & 39 & 26 & 18 & 14 & 9 & 7 & 6 & 5 & 5 & 8.5 \\
\hline 2012 & 28 & 14 & 8 & 5 & 2 & 1 & 1 & 1 & 1 & 5.9 \\
\hline 2013 & 20 & 13 & 8 & 4 & 3 & 3 & 3 & 3 & 3 & 4.1 \\
\hline 2014 & 6 & 4 & 4 & 4 & 3 & 3 & 3 & 3 & 3 & 1.2 \\
\hline Total & 275 & 199 & 150 & 109 & 77 & 60 & 48 & 35 & 28 & \\
\hline Occurrence \% & 33.8 & 24.5 & 18.5 & 13.4 & 9.5 & 7.4 & 5.9 & 4.3 & 3.4 & \\
\hline
\end{tabular}

Table 4. Number of downsizings of LCCs by year 


\begin{tabular}{|l|ccccccccc|}
\hline \multirow{2}{*}{ Year } & \multicolumn{7}{|c|}{ Reductions in seat capacity by LCCs higher than } \\
\cline { 2 - 9 } & $20 \%$ & $30 \%$ & $40 \%$ & $50 \%$ & $60 \%$ & $70 \%$ & $80 \%$ & $90 \%$ & $100 \%$ \\
\hline 1998 & 2 & 1 & 1 & 0 & 0 & 0 & 0 & 0 & 0 \\
1999 & 1 & 1 & 1 & 0 & 0 & 0 & 0 & 0 & 0 \\
2000 & 1 & 1 & 0 & 0 & 0 & 0 & 0 & 0 & 0 \\
2001 & 1 & 1 & 0 & 0 & 0 & 0 & 0 & 0 & 0 \\
2002 & 4 & 2 & 1 & 0 & 0 & 0 & 0 & 0 & 0 \\
2003 & 1 & 1 & 1 & 1 & 1 & 0 & 0 & 0 & 0 \\
2004 & 1 & 0 & 0 & 0 & 0 & 0 & 0 & 0 & 0 \\
2005 & 0 & 0 & 0 & 0 & 0 & 0 & 0 & 0 & 0 \\
2006 & 2 & 1 & 1 & 1 & 1 & 1 & 1 & 1 & 0 \\
2007 & 6 & 5 & 4 & 4 & 3 & 2 & 1 & 0 & 0 \\
2008 & 25 & 19 & 16 & 9 & 5 & 3 & 1 & 1 & 0 \\
2009 & 21 & 13 & 8 & 7 & 6 & 3 & 1 & 0 & 0 \\
2010 & 4 & 4 & 3 & 1 & 0 & 0 & 0 & 0 & 0 \\
2011 & 9 & 8 & 4 & 3 & 3 & 1 & 1 & 1 & 1 \\
2012 & 8 & 4 & 1 & 0 & 0 & 0 & 0 & 0 & 0 \\
2013 & 1 & 1 & 1 & 0 & 0 & 0 & 0 & 0 & 0 \\
2014 & 1 & 0 & 0 & 0 & 0 & 0 & 0 & 0 & 0 \\
\hline Total & 88 & 62 & 42 & 26 & 19 & 10 & 5 & 3 & 1 \\
\hline Occurrence\% & 26.5 & 18.7 & 12.7 & 7.8 & 5.7 & 3.0 & 1.5 & 0.9 & 0.3 \\
\hline
\end{tabular}

Table 5. Number of downsizings by LCCs by year in airports with at least five aircrafts based

\begin{tabular}{|c|cccccccccc|}
\hline \multirow{3}{*}{ Continent } & \multicolumn{7}{|c|}{ Reductions in seat capacity by LCCs higher than } \\
\cline { 2 - 10 } Europe & $20 \%$ & $30 \%$ & $40 \%$ & $50 \%$ & $60 \%$ & $70 \%$ & $80 \%$ & $90 \%$ & $100 \%$ \\
\hline \multirow{3}{*}{ North America } & 177 & 134 & 109 & 84 & 60 & 47 & 39 & 28 & 21 \\
& $39.8 \%$ & $30.1 \%$ & $24.5 \%$ & $18.9 \%$ & $13.5 \%$ & $10.6 \%$ & $8.8 \%$ & $6.3 \%$ & $4.7 \%$ \\
South America & 66 & 46 & 31 & 17 & 11 & 7 & 3 & 1 & 1 \\
& $27.5 \%$ & $19.2 \%$ & $12.9 \%$ & $7.1 \%$ & $4.6 \%$ & $2.9 \%$ & $1.3 \%$ & $0.4 \%$ & $0.4 \%$ \\
Asia & 19 & 13 & 7 & 6 & 5 & 5 & 5 & 5 & 5 \\
& $35.8 \%$ & $24.5 \%$ & $13.2 \%$ & $11.3 \%$ & $9.4 \%$ & $9.4 \%$ & $9.4 \%$ & $9.4 \%$ & $9.4 \%$ \\
Africa & 11 & 6 & 3 & 2 & 1 & 1 & 1 & 1 & 1 \\
& $23.9 \%$ & $13 \%$ & $6.5 \%$ & $4.3 \%$ & $2.2 \%$ & $2.2 \%$ & $2.2 \%$ & $2.2 \%$ & $2.2 \%$ \\
Total & 2 & 0 & 0 & 0 & 0 & 0 & 0 & 0 & 0 \\
& $50 \%$ & $0 \%$ & $0 \%$ & $0 \%$ & $0 \%$ & $0 \%$ & $0 \%$ & $0 \%$ & $0 \%$ \\
& 275 & 199 & 150 & 109 & 77 & 60 & 48 & 35 & 28 \\
& $33.8 \%$ & $24.5 \%$ & $18.5 \%$ & $13.4 \%$ & $9.5 \%$ & $7.4 \%$ & $5.9 \%$ & $4.3 \%$ & $3.4 \%$ \\
\hline
\end{tabular}


Table 6. Number of downsizings by continent and their percentages with respect to number of airport-LCC

pairs considered in the analysis

\begin{tabular}{|c|cccccccccc|}
\hline \multirow{2}{*}{ EU Country } & \multicolumn{7}{|c|}{ Reductions in seat capacity by LCCs higher than } \\
\cline { 2 - 10 } Spain & $20 \%$ & $30 \%$ & $40 \%$ & $50 \%$ & $60 \%$ & $70 \%$ & $80 \%$ & $90 \%$ & $100 \%$ \\
\hline \multirow{3}{*}{ United Kingdom } & 30 & 22 & 17 & 11 & 5 & 1 & 1 & 1 & 1 \\
& $35.7 \%$ & $26.2 \%$ & $20.2 \%$ & $13.1 \%$ & $6 \%$ & $1.2 \%$ & $1.2 \%$ & $1.2 \%$ & $1.2 \%$ \\
Germany & 36 & 27 & 22 & 18 & 11 & 8 & 8 & 6 & 5 \\
& $45.6 \%$ & $34.2 \%$ & $27.8 \%$ & $22.8 \%$ & $13.9 \%$ & $10.1 \%$ & $10.1 \%$ & $7.6 \%$ & $6.3 \%$ \\
Italy & 43 & 38 & 31 & 26 & 21 & 17 & 14 & 7 & 4 \\
& $59.7 \%$ & $52.8 \%$ & $43.1 \%$ & $36.1 \%$ & $29.2 \%$ & $23.6 \%$ & $19.4 \%$ & $9.7 \%$ & $5.6 \%$ \\
France & 14 & 10 & 8 & 6 & 5 & 5 & 5 & 5 & 5 \\
& $25.5 \%$ & $18.2 \%$ & $14.5 \%$ & $10.9 \%$ & $9.1 \%$ & $9.1 \%$ & $9.1 \%$ & $9.1 \%$ & $9.1 \%$ \\
Sweden & 4 & 2 & 1 & 1 & 1 & 1 & 1 & 1 & 0 \\
& $23.5 \%$ & $11.8 \%$ & $5.9 \%$ & $5.9 \%$ & $5.9 \%$ & $5.9 \%$ & $5.9 \%$ & $5.9 \%$ & $0 \%$ \\
& 3 & 1 & 1 & 1 & 0 & 0 & 0 & 0 & 0 \\
Norway & $20 \%$ & $6.7 \%$ & $6.7 \%$ & $6.7 \%$ & $0 \%$ & $0 \%$ & $0 \%$ & $0 \%$ & $0 \%$ \\
& 3 & 3 & 3 & 2 & 2 & 2 & 1 & 1 & 0 \\
& $21.4 \%$ & $21.4 \%$ & $21.4 \%$ & $14.3 \%$ & $14.3 \%$ & $14.3 \%$ & $7.1 \%$ & $7.1 \%$ & $0 \%$ \\
& 7 & 5 & 5 & 3 & 3 & 3 & 2 & 2 & 2 \\
& $53.8 \%$ & $38.5 \%$ & $38.5 \%$ & $23.1 \%$ & $23.1 \%$ & $23.1 \%$ & $15.4 \%$ & $15.4 \%$ & $15.4 \%$ \\
\hline
\end{tabular}

Table 7. Number of downsizings in the EU countries with greater presence of LCCs and their percentages with respect to number of airport-LCC pairs considered in the analysis

\begin{tabular}{|c|c|c|c|c|c|c|c|c|c|c|}
\hline \multirow{2}{*}{ LCC } & \multicolumn{9}{|c|}{ Reductions in seat capacity by LCCs higher than } & \multirow{2}{*}{$\begin{array}{l}\% \text { of downsizing compared with } \\
\text { the n. of airport considered }\end{array}$} \\
\hline & $20 \%$ & $30 \%$ & $40 \%$ & $50 \%$ & $60 \%$ & $70 \%$ & $80 \%$ & $90 \%$ & $100 \%$ & \\
\hline Ryanair & 57 & 40 & 27 & 22 & 13 & 10 & 7 & 6 & 6 & 57 \\
\hline Airberlin & 25 & 18 & 13 & 10 & 7 & 4 & 4 & 2 & 1 & 71 \\
\hline TUIfly.com & 12 & 11 & 10 & 9 & 7 & 6 & 5 & 4 & 2 & 80 \\
\hline Southwest Airlines & 43 & 30 & 19 & 8 & 4 & 2 & 2 & 1 & 1 & 53 \\
\hline Condor Flugdienst & 13 & 12 & 10 & 8 & 5 & 2 & 1 & 0 & 0 & 100 \\
\hline EasyJet & 18 & 11 & 9 & 6 & 4 & 4 & 4 & 2 & 2 & 33 \\
\hline JetBlue Airways & 9 & 9 & 8 & 5 & 3 & 3 & 1 & 0 & 0 & 26 \\
\hline
\end{tabular}




\begin{tabular}{|l|ccccccccc|r|}
\cline { 2 - 6 } & 17 & 11 & 5 & 4 & 3 & 3 & 3 & 3 & 3 & 46 \\
FlyBE & 9 & 7 & 6 & 4 & 2 & 2 & 2 & 0 & 0 & $47 \%$ \\
\hline
\end{tabular}

Table 8. Number of downsizings by the main LCCs

\begin{tabular}{|l|rrrrrrrrr|}
\hline \multirow{2}{*}{ Dominance by LCCs } & \multicolumn{7}{|c|}{ Reductions in seat capacity by LCCs higher than } \\
\cline { 2 - 10 } & $20 \%$ & $30 \%$ & $40 \%$ & $50 \%$ & $60 \%$ & $70 \%$ & $80 \%$ & $90 \%$ & $100 \%$ \\
\hline Ryanair (\%) & 49 & 52 & 53 & 54 & 54 & 52 & 40 & 36 & 25 \\
Airberlin (\%) & 20 & 23 & 26 & 31 & 36 & 33 & 34 & 34 & 7 \\
TUIfly.com (\%) & 11 & 14 & 16 & 16 & 17 & 21 & 21 & 21 & 25 \\
Southwest Airlines (\%) & 34 & 37 & 40 & 46 & 43 & 21 & 16 & 16 & 3 \\
Condor Flugdienst (\%) & 10 & 13 & 13 & 13 & 12 & 12 & 8 & 11 & \\
EasyJet (\%) & 22 & 22 & 18 & 21 & 24 & 24 & 24 & 24 & 15 \\
JetBlue Airways (\%) & 14 & 10 & 10 & 11 & 13 & 7 & 7 & 7 & \\
Gol (\%) & 40 & 40 & 41 & 43 & 45 & 55 & 55 & 55 & 55 \\
FlyBE (\%) & 31 & 40 & 48 & 41 & 34 & 32 & 32 & 32 & \\
\hline Average (\%) & 29 & 30 & 30 & 29 & 29 & 26 & 25 & 24 & 22 \\
\hline
\end{tabular}

Table 9. Average dominance level by LCCs in terms of seat capacity before downsizing

\begin{tabular}{|l|ccccccccc|}
\hline \multirow{2}{*}{ Airport size ('000) } & \multicolumn{7}{|c|}{ Reductions in seat capacity by LCCs higher than } \\
\cline { 2 - 10 } & $20 \%$ & $30 \%$ & $40 \%$ & $50 \%$ & $60 \%$ & $70 \%$ & $80 \%$ & $90 \%$ & $100 \%$ \\
\hline Ryanair & 6,852 & 7,317 & 7,835 & 5,816 & 6,210 & 4,850 & 5,072 & 4,897 & 5,562 \\
Airberlin & 17,139 & 14,950 & 15,497 & 12,819 & 9,988 & 12,959 & 10,126 & 10,126 & 18,655 \\
TUIfly.com & 21,490 & 20,696 & 15,927 & 16,962 & 16,152 & 10,681 & 11,308 & 10,835 & 9,212 \\
Southwest Airlines & 18,374 & 14,858 & 11,762 & 9,557 & 14,861 & 26,530 & 24,333 & 24,333 & 45,514 \\
Condor Flugdienst & 21,692 & 11,097 & 11,597 & 12,231 & 12,314 & 14,694 & 24,936 & 7,210 & \\
easyJet & 17,450 & 18,576 & 16,461 & 15,046 & 6,202 & 6,334 & 6,334 & 6,334 & 5,654 \\
JetBlue Airways & 24,579 & 24,326 & 24,326 & 15,285 & 13,630 & 20,578 & 20,578 & 8,050 & \\
Gol & 7,489 & 4,497 & 4,860 & 6,830 & 6,570 & 4,945 & 4,945 & 4,945 & 4,945 \\
FlyBE & 11,924 & 15,594 & 7,199 & 8,180 & 11,291 & 19,116 & 19,116 & 19,116 & \\
\hline Average & 15,142 & 14,876 & 14,576 & 13,612 & 13,463 & 15,371 & 15,585 & 13,823 & 13,556 \\
\hline
\end{tabular}

Table 10. Average size of airports suffering LCC downsizings (seat capacity in thousands)

\begin{tabular}{|c|ccccccccc|}
\hline \multirow{2}{*}{ LCC seat recovery } & \multicolumn{8}{|c|}{ Reductions in seat capacity by LCCs higher than } \\
\cline { 2 - 9 } & $20 \%$ & $30 \%$ & $40 \%$ & $50 \%$ & $60 \%$ & $70 \%$ & $80 \%$ & $90 \%$ & $100 \%$ \\
\hline Number of cases & 275 & 199 & 150 & 109 & 77 & 60 & 48 & 35 & 28 \\
Seat recovery & 42 & 25 & 15 & 8 & 6 & 4 & 3 & 2 & 1
\end{tabular}




\begin{tabular}{|c|ccccccccc|} 
\% of total cases & 15.3 & 12.6 & 10.0 & 7.3 & 7.8 & 6.7 & 6.3 & 5.7 & 3.6 \\
\hline At least 5 aircrafts based & 88 & 62 & 42 & 26 & 19 & 10 & 5 & 3 & 1 \\
\% of total case & 32.0 & 31.2 & 28.0 & 23.9 & 24.7 & 16.7 & 10.4 & 8.6 & 3.6 \\
Seats recovery & 8 & 4 & 3 & 1 & 1 & 0 & 0 & 0 & 0 \\
\% of cases & 9.1 & 6.5 & 7.1 & 3.8 & 5.3 & 0.0 & 0.0 & 0.0 & 0.0 \\
\hline
\end{tabular}

Table 11 Seat recovery by LCCs in airports that suffered downsizing

\begin{tabular}{l|r}
\multicolumn{1}{c}{ variable } & $Y 20($ drop $>20 \%)$ \\
\hline Seats_offered & $-1.41010^{-06 * * *}$ \\
\hline N_aircraftbased & $-0.019 *$ \\
N_year & $0.044 * *$ \\
\hline Mkt_share & $-1.738^{* * *}$ \\
\hline LCCcompetitor & $6.77710^{-03 *}$ \\
LCC_growth & $-6.052 * * *$ \\
Alt_airport_size & $4.16110^{-08 * *}$ \\
\hline Alt_airport_size^2 & $-5.78010^{-16 *}$ \\
Country_growth & $-3.342^{*} * *$ \\
Alt_airport_distance & $-0.004 *$ \\
Ryanair_dummy & $0.935^{*} * *$ \\
\hline const & $-0.981 * * *$
\end{tabular}

Table 12 Determinants of LCC drops greater than 20 per cent 


\section{Figures}

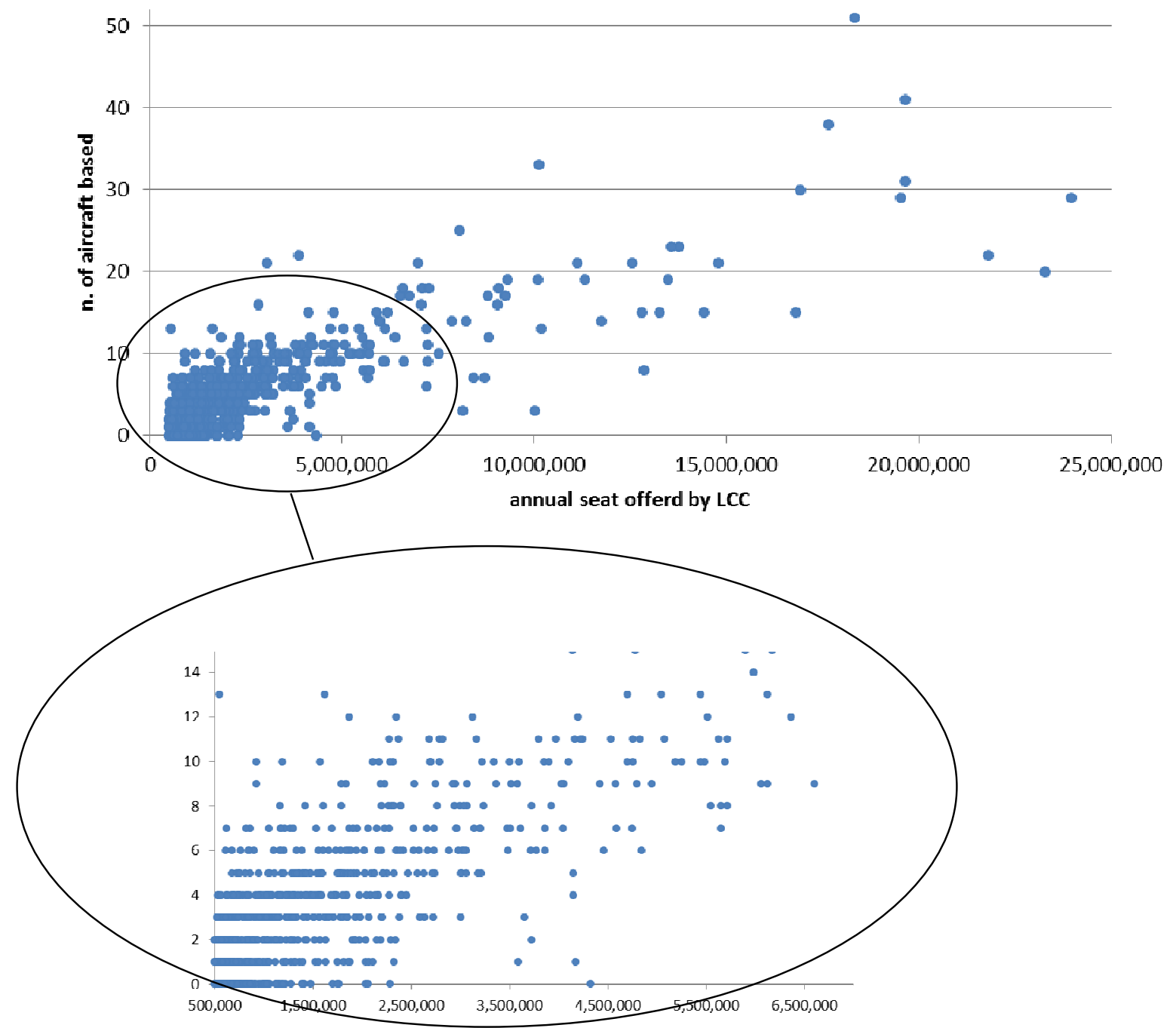

Figure 1. Seats-aircrafts based relation 


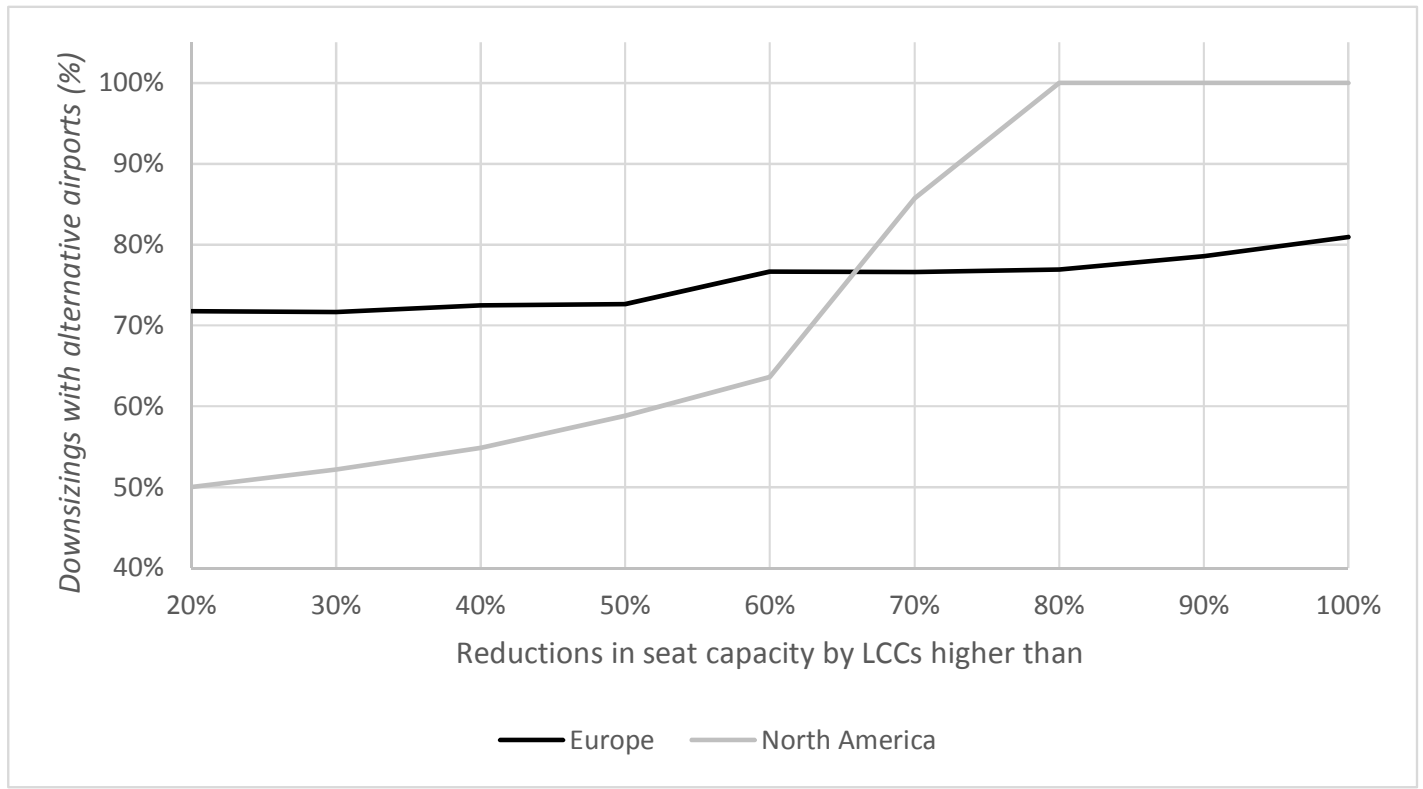

Figure 2. Likelihood of downsizings with alternative airports in Europe and North America. 


\section{Appendix}

\begin{tabular}{|l|}
\hline \multicolumn{1}{|c|}{ Low-Cost Carrier } \\
\hline Aer Arann \\
Aero Asia International \\
Aerolineas Mesoamericanas \\
Air Baltic \\
Air Berlin \\
Air Europe \\
Air Finland \\
Air Luxor \\
Airtran \\
ALPI Eagles \\
ATA \\
Avianova \\
bmibaby \\
Canada 3000 \\
Centralwings \\
Centre Avia Airlines \\
China Xinjiang Airlines \\
Condor Flugdienst \\
Dau Air \\
dba \\
easyJet \\
Easyjet Switzerland \\
Excel Airways \\
First Choice Airways \\
Fly Me Sweden \\
\hline
\end{tabular}

\begin{tabular}{|l|}
\hline \multicolumn{1}{|c|}{ Low-Cost Carrier } \\
\hline Flybaboo \\
FlyBE \\
Flyglobespan \\
flynordic \\
Germanwings \\
Gol Transportes Aereos \\
Golden Air \\
Hapag Lloyd Express \\
HapagFly \\
Helvetic Airways \\
InterSky \\
Itali Airlines \\
Jet2 \\
JetBlue Airways \\
Jetx \\
KD Avia \\
Kuzu Airways Cargo \\
Livingston \\
LTU International Airways \\
Malmo Aviation \\
Monarch Airlines \\
MyAir.com \\
National Airlines \\
Norwegian Air Shuttle \\
Perm Airlines \\
\hline
\end{tabular}

\begin{tabular}{|l|}
\hline \multicolumn{1}{|c|}{ Low-Cost Carrier } \\
\hline Ryanair \\
Sky Europe Airlines Hungary \\
Skyeurope Airlines \\
Smart Wings \\
Southwest Airlines \\
SpiceJet \\
Spirit Airlines \\
Sriwijaya \\
Sterling Airlines \\
Swedline Express \\
Tiger Airways \\
Transavia Airlines \\
USA 3000 Airlines \\
Valuair \\
Vintage Props \\
Virgin Blue \\
Virgin Express \\
VLM Airlines \\
Vueling Airlines \\
Westjet \\
Wind Jet \\
Wizzair \\
ZanAir \\
Zip \\
Zoom Airlines \\
\hline
\end{tabular}

Table A1. List of the LCCs considered in this study. 